\title{
Evaluating the joint effects of climate and land use change on runoff and pollutant loading in a rapidly developing watershed
}

\author{
Nasrin Alamdari ${ }^{a}$, Peter Claggett ${ }^{b}$, David J. Sample ${ }^{\text {c, }}$, Zachary M. Easton ${ }^{c}$, \\ Mohammad Nayeb Yazdi ${ }^{\mathrm{d}}$ \\ ${ }^{a}$ FAMU-FSU College of Engineering, United States \\ ${ }^{\mathrm{b}}$ U.S. Geological Survey, Chesapeake Bay Office, United States \\ ${ }^{\mathrm{c}}$ Department of Biological System Engineering, Virginia Polytechnic Institute and State University, United States \\ ${ }^{\mathrm{d}}$ School of Environment and Natural Resources, Ohio State University, United States
}

\section{A R T I C L E I N F O}

Handling editor: Bin Chen

\section{Keywords:}

Urban stormwater

Climate change

Land use/land cover change

Urban stormwater modeling

Nonpoint source pollution

\begin{abstract}
A B S T R A C T
Communities are coping with changes in runoff quantity and quality, stemming mainly from changes in climate and land use/land cover (LULC); there is a need to identify the most adaptable strategies that improve community resilience. However, the joint impacts of climate and LULC change have rarely been assessed at local scales. To address these needs, we assessed the response of runoff and pollutant loads from Broad Run, a rapidly developing watershed in northern Virginia, to projected climate and LULC change. Climate data from two downscaled Global Climate Models (GCMs) were used to force an urban watershed model, the Storm Water Management Model (SWMM), while forecasts of LULC change were derived from the Chesapeake Bay Land Change Model (CBLCM). Two Representative Concentration Pathways (RCPs), 4.5 and 8.5, a historic baseline (1995-2020), and projected periods (2040-2065); and four LULC change scenarios designated agricultural conservation (AC), forest conservation (FC), growth management (GM), and historical trend (HT) were used to create a series of ensemble simulations of coupled LULC and climate change. Results indicated that, under RCP 8.5, annual precipitation is projected to increase substantially more than RCP 4.5. Projected LULC change resulted in a projected increase in imperviousness from $6.3 \%$ to $13.1 \%$. Results indicated that climate change will likely increase the seasonal variability of runoff, Total Suspended Solids (TSS), Total Nitrogen (TN), and Total Phosphorus (TP) for both RCPs. The largest increase for a single LULC change (without climate change) scenario for runoff, TSS, TN, and TP was 32.6\%, 33.4\%, 31.6\%, and 35.8\%, respectively. which occurred with the HT scenario. Results of LULC change also indicated that more pollutant loads were associated with increased imperviousness from increased urban development and loss of deciduous forests and grasslands. The largest increase for climate and LULC change scenarios in runoff, TSS, TN, and TP was $67.6 \%, 66.7 \%, 63.4 \%$, and $69.4 \%$, respectively, which occurred with the RCP 8.5 and HT scenarios. Similar, but smaller increases were obtained for other scenarios, suggesting that climate and LULC change may be synergistic, likely undermining watershed restoration efforts. The results of our study also indicate that runoff, TSS, TN, and TP are expected to be more affected by changes in future LULC than by projected changes in climate. Our study can be used to inform watershed restoration efforts, urban planning, and environmental policy. The combined impact of climate and LULC change will likely generate increased runoff, and nutrients and sediment loading, indicating that robust mitigation strategies are needed for watershed restoration to succeed.
\end{abstract}

\section{Introduction}

Recently, there has been much interest in the impacts of climate change on urban communities, particularly increases in runoff, flooding, and the development of adaptation and mitigation strategies that are intended to sustain the coupled human-natural systems of urban areas.

\footnotetext{
* Corresponding author. Hampton Roads Agricultural Research and Extension Center, Virginia Polytechnic and State University, 1444 Diamond Springs Rd, Virginia Beach, VA, 23455, 0017573633863, United States.

E-mail addresses: nalamdari@eng.famu.fsu.edu (N. Alamdari), pclaggett@chesapeake.net (P. Claggett), dsample@vt.edu (D.J. Sample), zeaston@vt.edu (Z.M. Easton), nayebyazdi.1@osu.edu (M. Nayeb Yazdi).
} 
Water resources management and hydrologic design have long relied on the principle of hydrologic stationarity, which assumes that future conditions will be statistically similar to that observed in the historical record. Climate change undermines this assumption, so new methods are needed to replace it (Milly et al., 2015). Climate change may lead to changes in temperature, precipitation intensity, and duration, and a rise in sea levels (Alamdari et al., 2020; Alamdari and Hogue, 2021; Hathaway et al., 2014; IPCC, 2014). At the same time, increasing urban development needed to accommodate growing urban populations, increasing the proportion of impervious surfaces, which results in increased runoff and pollutant loads (Abrishamchi et al., 2011; Salvadore et al., 2015).

Land cover in rapidly developing areas is transforming due to biophysical and socio-economic conditions. A comprehensive understanding of these conditions can assist urban planners, decision-makers, and policymakers select more sustainable and resilient watershed restoration strategies. Social-ecological models use spatial statistical methods to better understand biophysical and socio-economic components and identify effective management solutions. For example, Kalantari et al. (2019) presented a coupled social-ecological system modeling approach for assessing the sustainable development of growing cities. Results indicated that the coupled social-ecological system approach could provide a means of assessing the impacts of urbanization on hydrological processes.

Urban development increases nutrient export (Foley et al., 2005), and, as nutrients accumulate in water bodies, eutrophication ensues. Perhaps the most well-known example of this phenomenon (and the most relevant to this paper) is the Chesapeake Bay Estuary (National Research Council, 2000). Roberts et al. (2009) predicted that increased imperviousness and urbanization in the future could increase nutrient loads to the Chesapeake Bay by $56 \%$, leading to eutrophication and harmful algal blooms. While previous studies focused on the effects of land use/land cover (LULC) change on hydrological processes, most are based only on historical data and are often limited to a single land cover class, e.g., only agricultural or urban development (Hovenga et al., 2016; Johnson et al., 2012; Schilling et al., 2010). This fails to provide a full picture of the impact of changes in the LULC patterns on hydrologic processes, particularly in urban environments.

Climate change may amplify the effects of LULC change, increasing pollutants in downstream water bodies. Several studies have evaluated the effects of climate change only on runoff and water quality (Alamdari, 2018; Alamdari et al., 2017, 2018; Giuffria et al., 2017; Hathaway et al., 2014; Semadeni-Davies, 2006). Multiple studies have used hydrologic models to evaluate coupled climate and LULC change and assess the impacts of each on hydrology (Schilling et al., 2008; Semadeni-Davies et al., 2008; Yan et al., 2013); however, most of these studies have focused on runoff quantity, not quality. Best Management Practices (BMPs) are often employed to reduce runoff and treat pollutants such as nutrients and sediment through biological, chemical, and physical processes. BMPs are often used in watershed restoration; however, predicting their cumulative response and effects may require complex models; the performance of these practices varies substantially (Ahmadisharaf et al., 2016, 2021; Lintern et al., 2020; Nayeb Yazdi et al., 2019b).

An active watershed restoration effort is currently underway in the Chesapeake Bay Watershed. This is in part due to the imposition of a Total Maximum Daily Load (TMDL) for the Chesapeake Bay; effectively limiting nitrogen $(\mathrm{N})$, phosphorus $(\mathrm{P})$, and sediment discharged into Bay tributaries from municipal wastewater, urban stormwater, and agricultural sources (USEPA, 2010a). These pollutants cause a variety of impacts in the Bay, including eutrophication, harmful algal blooms, and loss of biodiversity and aquatic habitats. Several studies have focused on water quality-related issues due to agricultural activities in the Chesapeake Bay watersheds (Bosch et al., 2018; Fisher et al., 2021; Fleming et al., 2021; Jordan et al., 2018; Kleinman et al., 2019; Lacher et al., 2019; Pan et al., 2021; Wagena et al., 2018). However, there is a lack of research on pollution originating from urban activities and population growth. In addition, most of these studies focused on climate or LULC change individually and did not consider their joint impacts. In the face of looming climate and LULC change, there is a pressing need for integrated frameworks that can model not only the individual but also the coupled effects of these changes. Furthermore, previous similar studies focused on evaluating the changes in urban streamflow under projected climate or LULC change and did not consider impacts on water quality. Further research is needed to better address the joint effect of climate and LULC change in a rapidly developing watershed to assess changes in runoff, as well as TSS, TN, and TP since these variables are highly localized and are very sensitive to precipitation and LULC. Understanding the relationship between LULC, climate, and surface runoff quantity and quality is necessary for developing effective watershed mitigation strategies such as placing and selecting BMPs (Rajaei et al., 2021).

Compliance with the Chesapeake Bay TMDL, set for 2025, is expected to prevent eutrophication in the estuary and restore aquatic habitats. Evaluations of individual and joint effects of climate and LULC changes on runoff quality and quantity in a rapidly developing area have not been adequately addressed, resulting in a lack of understanding of the scale of their effects. Our research is the first study on the Chesapeake Bay to assess the coupled effects of climate and LULC change on runoff and pollutant loads from a rapidly developing watershed that is a tributary to the Bay. Advances in downscaling methods coupled with continuous simulation models make it feasible to assess water quantity and quality while incorporating climate and LULC changes (Alamdari et al., 2020; Claggett and Thompson, 2012). These studies used downscaling methods to either evaluate the effects of climate or LULC change on water quality but did not assess them jointly. Most of the previous research on modeling the joint effects of climate and LULC change on hydrology have focused on agricultural land conversion and conversion of other LULC to agriculture (Giri et al., 2019). There is a need to evaluate the joint effects of climate and LULC changes in rapidly developing urban watersheds to assess their combined impacts and identify mitigation strategies that can help in adapting to these changes. Existing studies have limitations, such as projections based on one climate model, a single future climate pathway, and old emission scenarios (e.g., Coupled Model Intercomparison Project Phase or CMIP-4), or use future LULC predictions from simple regression models that fail to account for dynamic transformation of various LULCs and spatial patterns of LULC, among others. These limitations can increase uncertainties in the assessment of impacts on urban hydrology and water quality.

To address these research gaps, we applied the Stormwater Management Model (SWMM) (Rossman, 2015) to the rapidly developing Broad Run watershed (BRW), a $197 \mathrm{~km}^{2}$ watershed in Loudoun County, Virginia, United States (Fig. 1). SWMM has been successfully applied in various urban watersheds across the US (Alamdari and Sample, 2019; Jefferson et al., 2017; Salvadore et al., 2015). SWMM is used at an hourly time scale with a variety of projected climate and LULC change scenarios from Global Climate Models (GCMs) and the Chesapeake Bay Land Cover Model (CBLCM). Models such as these can be used to assess land use policies and inform decision-makers at local and regional levels; they can also be used to plan, design, and/or modify BMPs and other mitigation measures. Loudoun County is one of the fastest-growing counties in the United States (Loudoun County, 2008). Rapid population growth will likely negatively impact the County's surface and groundwater resources. Broad Run is the most developed watershed in the County, thus BRW is an ideal location for our research. With a population of 280,000 (Loudoun County, 2008), the Loudoun County Board of Supervisors has encouraged and funded projects that evaluate existing hydrology and water quality. The BRW is expected to experience a significant population increase over the next several decades (Roth et al., 2014). The BRW consists of 19 sub-watersheds (Fig. 2); with the highest population densities are located in the northeastern portion of the 

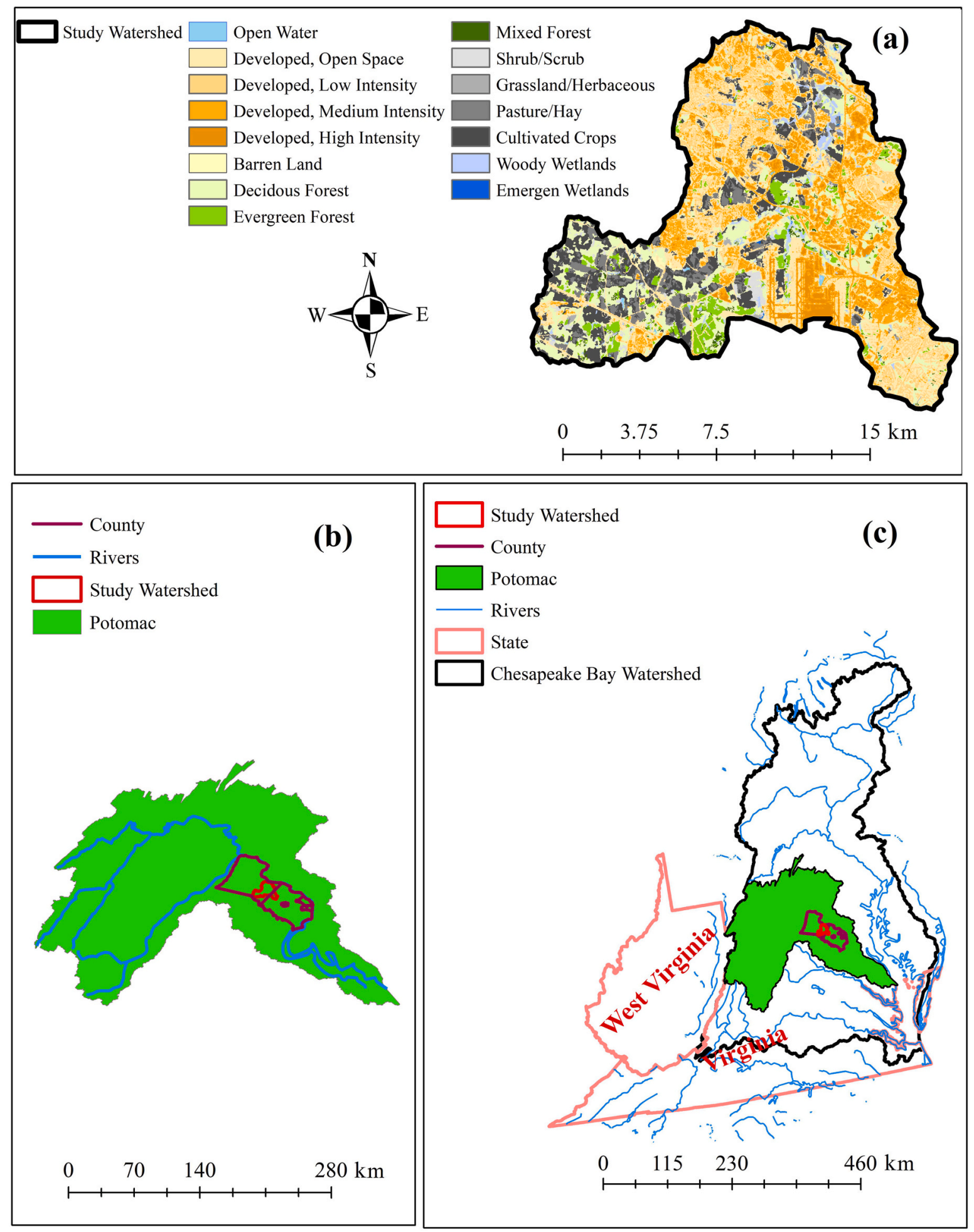

Fig. 1. (a) Broad Run land use/land cover, 2011; (b) Broad Run Watershed and Loudoun County; (c) Chesapeake Bay Watershed and States. Source: National Land Cover Database (NLCD) (Homer et al., 2012).

watershed. The specific objectives of this study were to i) evaluate potential impacts of climate change in the near future (2040-2070) on runoff and pollutant loads (TSS, TN, and TP); and ii) estimate the effect of land use change both alone and jointly with climate on hydrology and water quality in the BRW; (iii) compare the relative impact of LULC and climate change on the runoff and pollutant loads in an urban watershed.

\section{Materials and methods}

\subsection{Watershed description}

Broad Run is located within the Piedmont physiographic region south of the City of Leesburg and west of Washington Dulles International Airport. Relief is low (slope $<\sim 5.4 \%$ ), the average elevation is 80 $\mathrm{m}$, and the geology of the area consists mainly of fluvial soils and those 

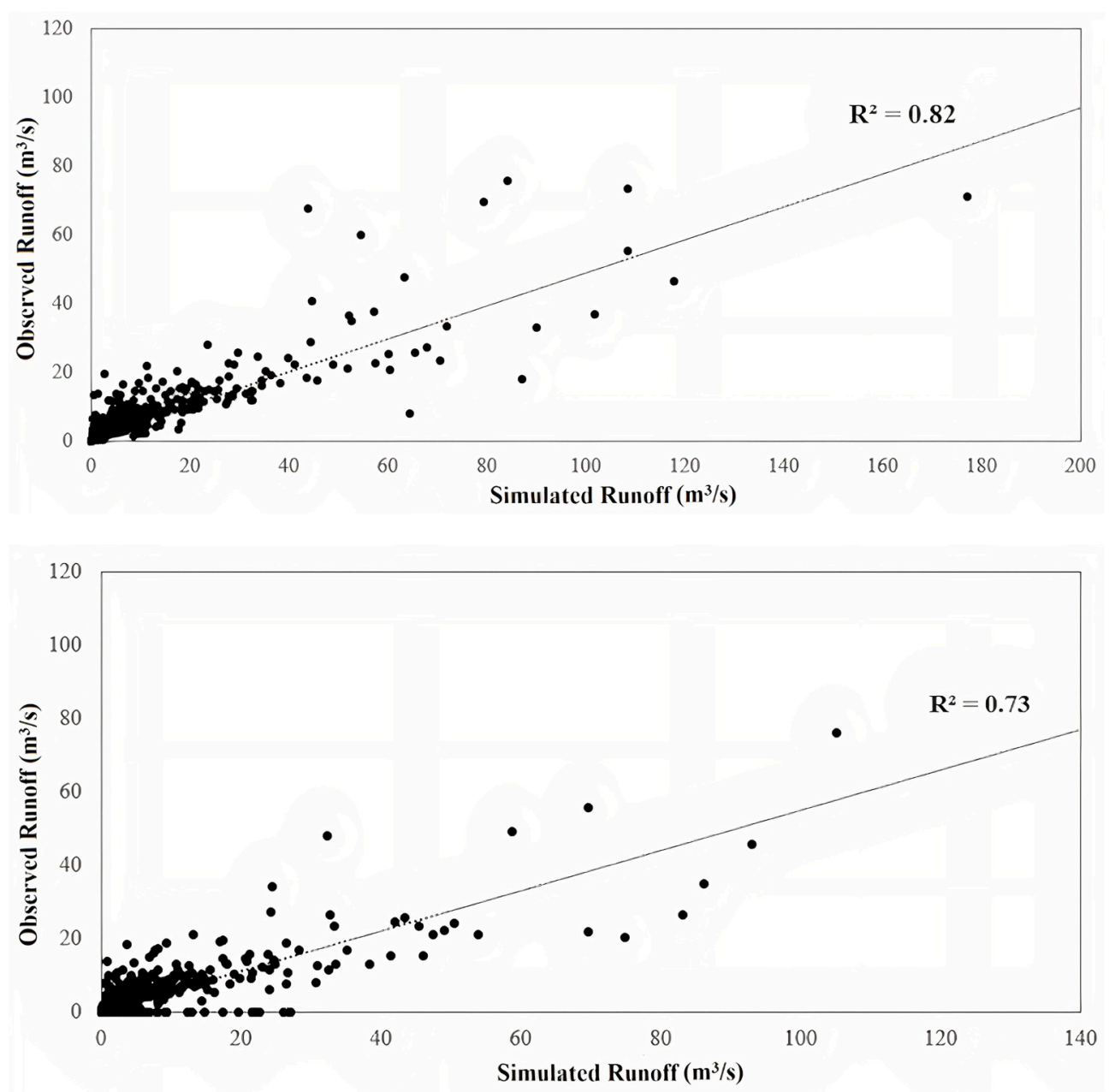

Fig. 2. Runoff calibration and validation for Broad Run near Leesburg, Virginia.

of lacustrine origin (Roth et al., 2014). Subwatershed delineations were performed using geographic information system (GIS) data provided by Loudoun and Fairfax Counties, with an average subwatershed size of 10 $\mathrm{km}^{2}$. The dominant soil type in the study area is hydrologic soil group B, with moderate infiltration capacity (Natural Resources Conservation Service, 2015). Half of the watershed soils are prone to high erosion losses (Roth et al., 2014). The watershed location and LULC distribution for the year 2011 are shown in Fig. 1; the most dominant LULC is urban-residential. Tables 1 and 2 provide soil and LULC breakdowns for

Table 1

Existing land use/landcover in the Broad Run watershed.

\begin{tabular}{ll}
\hline LULC Type & Existing (\%) \\
\hline Open Water & 0.4 \\
Developed, Open Space & 32.2 \\
Developed, Low Intensity & 12.5 \\
Developed, Medium Intensity & 6.6 \\
Developed, High Intensity & 1.5 \\
Barren Land (Rock/Sand/Clay) & 0.02 \\
Deciduous Forest & 35.9 \\
Evergreen Forest & 2.1 \\
Mixed Forest & 1.4 \\
Shrub/Scrub & 0.9 \\
Grassland/Herbaceous & 0.06 \\
Pasture/Hay & 1 \\
Cultivated Crops & 0.8 \\
Woody Wetlands & 4.3 \\
Emergent Herbaceous Wetlands & 0.01 \\
\hline
\end{tabular}

Source: National Land Cover Database (Homer et al., 2012).
Table 2

Existing soil in the broad run watershed.

\begin{tabular}{ll}
\hline LULC Type & Existing (\%) \\
\hline A Soils & 0 \\
B Soils & 9.2 \\
C Soils & 22.8 \\
D Soils & 48.7 \\
B/D Soils & 5 \\
C/D Soils & 5.9 \\
\hline
\end{tabular}

Source: Soil Survey Geographic Database (SSURGO) (Natural Resources Conservation Service, 2015).

the watershed.

\subsection{Study data}

Precipitation data was acquired for Dulles International Airport National Weather Service station 448903 from the National Centers for Environmental Information (NCEI). National Hydraulic data (e.g., channel cross-sections) were obtained from Fairfax and Loudoun Counties. Subwatershed delineations were performed using GIS data as shown in Fig. 2, with an average subwatershed size of $10 \mathrm{~km}^{2}$. All subwatershed parameters needed for the SWMM model (e.g., hydraulic conductivity, slope, etc.) were calculated with GIS operations using areal weighting. In this study, TSS, TN, and TP were estimated using event mean concentrations (EMCs) as outlined in Alamdari et al. (2020, 2017). Data from two GCM - Regional Climate Models (GCM-RCM) 
combinations were used, including 1) the Goddard Institute for Space Studies Model E, coupled with the Russell ocean model (GISS-E2-R); and 2) the Community Climate System Model, version 4 (CCSM4) (Taylor et al., 2012). These models were selected based on a comparison of hindcast GCM predictions with observed historical data. LULC scenarios included agricultural conservation (AC), forest conservation (FC), growth management (GM), and historic trend (HT) using the CBLCM model developed by the U.S. Geological Survey (USGS) for the Chesapeake Bay watershed. Groundwater parameters were obtained from the geologic map of Loudoun County (Drake and Lee, 1989; Southworth et al., 2007) and the Soil Survey Geographic Database (SSURGO) database (Natural Resources Conservation Service, 2015). All subwatershed parameters needed for the SWMM model (e.g., hydraulic conductivity, slope, etc.) were calculated with GIS using areal weighting. Groundwater parameters for each subwatershed were acquired from calibration of the model and considering the geologic map. Evaporation is simulated in SWMM using the Hargreaves equation, which fits a sine wave through the daily temperature range obtained from the NCEI (Hargreaves and Samani, 1985) to calculate hourly evaporation (Rossman, 2015).

\subsection{Hydrologic and water quality modeling}

SWMM version 5.1.014 was used for all watershed modeling. The model can simulate EMCs and watershed loads. It has been applied extensively to urban watersheds; it simulates rainfall-runoff hydrology, hydraulics of a stormwater collection and conveyance system, and runoff quality and treatment provided by BMPs (Niazi et al., 2017). A full dynamic wave for flow routing was used to simulate non-uniform flows (Rossman, 2015), which are commonly observed in urban drainage systems. Based on the 2011 National Land Cover Dataset (NLCD), approximately $28.1 \%$ of the watershed is impervious at present, approximately $53 \%$ of the watershed is developed, and $38 \%$ is forested.

SWMM simulates treatment by using an estimated EMC wash-off during wet events. We used unique EMC values for each LULC to account for the variability of pollutant loads due to the LULC change. These EMCs values were obtained from the National Urban Runoff Program (NURP) and data from the Chesapeake Bay watershed (Price et al., 2013; Schueler, 2011; USEPA, 2010b).

\subsection{Calibration and validation}

SWMM was calibrated using an autocalibration tool, RSWMM-Cost (Alamdari, 2016; Alamdari and Sample, 2019), which adjusts specific model parameters such as hydraulic width, hydraulic conductivity, slope, and imperviousness for all 19 subwatersheds, each within a specified range, derived from SWMM guidelines. Simulations were compared with observations from the USGS stream gauge \# 01644280, Broad Run near Leesburg, Virginia. Several metrics and/or an objective function such as correlation $\left(\mathrm{R}^{2}\right)$, Nash-Sutcliffe Efficiency Coefficient (NSE), and Percent Bias (PBIAS) were used to evaluate the model calibration. RSWMM-Cost improves the utility of SWMM by controlling its execution, manipulation of input and output files, and inclusion of specialized analysis tools. In addition to assisting in calibration, RSWMM-Cost assists in performing sensitivity analyses plotting duration curves (Alamdari et al., 2017), and cost optimization (Alamdari and Sample, 2019). Observed and simulated outputs were compared at the gaging station to find optimal parameter sets that match observed streamflow. Iterative searches were performed using the optimization engine to identify sets of best solutions where the observed and simulated are in good agreement. The model performance was graded based on Moriasi et al. (2015) and Ahmadisharaf et al. (2019). Calibration and validation were conducted on the periods of 2007-2012 and 2001-2006, respectively.

An assessment of runoff quality performance was also conducted by comparing the simulations with predicted water quality results by the Chesapeake Bay Watershed Model (CBWM) (Shenk and Linker, 2013).
CBWM is based on the Hydrological Simulation Program-Fortran (HSPF), a continuous, physically based, lumped-parameter model that simulates hydrology, sediment, and water quality constituents in the soil and streams (Donigian et al., 1995). The CBWM results for the BRW were used to calibrate water quality. This substitution relies on the fact that the CBWM has been extensively calibrated to facilitate the prediction of water quality in surface waters across the Chesapeake Bay watershed. The calibrated watershed model allows resource managers to simulate the large-scale effects of LULC changes and the implementation of BMPs on water quality. Water quality data for the BRW were available at a daily time scale from 2005 to 2015 .

\subsection{Climate change modeling}

To model anticipated climate change impacts, projections for climate variables were acquired from simulations of the Coupled Model Intercomparison Project Phase 5 (CMIP5) dataset (Taylor et al., 2012) from Lawrence Livermore National Laboratory database (https://gdo-dcp. ucllnl.org/downscaled_cmip_projections/). Two time periods, 1995-2020 and 2040-2065 were chosen to simulate baseline and future conditions. Two Representative Concentration Pathways, RCP 4.5 and 8.5 (Moss et al., 2010), were selected to represent medium and intensive greenhouse gas emission scenarios, respectively. Data from two GCM-RCM combinations were used: 1) the Goddard Institute for Space Studies Model E, coupled with the Russell Ocean model (GISS-E2-R); and 2) the Community Climate System Model, version 4 (CCSM4). These models were selected out of 32 models based on a comparison of hindcast GCM predictions (2040-2065) with observed (1995-2020) historical data. These GCM models were selected based on metrics such as bias, root mean square error (RMSE), and spatial correlation to quantify the errors relative to observed annual and annual near-surface air temperature based on the study by Sheffield et al. (2013) in the Northeast and Mid-Atlantic regions of the United States.

\subsection{Land use/land cover change modeling}

The CBLCM was developed to forecast urbanization in the Chesapeake Bay watershed and produces results at a $30 \mathrm{~m}$ resolution, a scale appropriate for watershed modeling. The model was developed by the USGS (Claggett, 2011; Claggett and Thompson, 2012). The CBLCM stochastically simulates the spatial location and extent of residential and commercial development for any specified time interval up to the year 2100. Fifteen classes of LULC were used in this study (Fig. 1) but were reclassified to six classifications for brevity. A future scenario represents a set of model inputs and plausible assumptions consistent with a logically coherent storyline. Four benchmark scenarios were developed to evaluate the CBLCM performance, explore the effects of exclusions such as zoning and land protection, and provide a meaningful set of benchmarks for comparison against stakeholder-generated scenarios. The five scenarios include "Historic Trends" (HT), "Growth Management" (GM), "Natural land Conservation" (FC), and "Agricultural Conservation" (AC). The CBLCM was parameterized based on changes observed over the 2000-2010 period when sprawl development patterns were prevalent. For all scenarios, exogenous population and employment projections were held constant to facilitate comparison. The CBLCM was used to simulate 101 iterations of each scenario from 2020 through 2055 in five-year increments. To help develop the LULC scenarios, the data included zoning, priority funding areas, transit stations, sewer service areas (existing and proposed), land use comprehensive plans (e.g., proposed future densities or zoning), special protection areas ${ }^{1}$ (e.g.,

\footnotetext{
${ }^{1}$ Note that by special protection areas, we mean areas that are either: 1) afforded special protection against urban development in county or state laws, regulations, or ordinances; or 2) have limited ability to support development due to environmental constraints.
} 
critical areas, riparian buffers, erosion-prone soils, flood zones), protected lands, agricultural districts, conservation priorities (i.e., farms, natural lands, and wetlands), and planned transportation improvements was collected from Maryland's Department of Natural Resources, Department of the Environment, and Department of Planning. Consulting with these agencies provided perspective on how growth patterns have occurred and might change in rural and urban settings and prompted dividing the demand for housing and employment into urban and rural zones.

\subsubsection{Historic Trends (HT)}

The HT scenario assumes that the forces, policies, and regulations that influenced development patterns over the 2000s will continue unabated into the future. Under this scenario, historical rates of infill development and urban vs rural development estimated by the CBLCM were assumed to continue indefinitely. Areas developed through 2013, emergent wetlands, open water, steep slopes, and public and protected lands were excluded from future development. Because the early $2000 \mathrm{~s}$ was a period of rapid, dispersed development, this scenario is the one most reflective of sprawling growth patterns.

\subsubsection{Growth management (GM)}

The GM scenario represents a move towards the implementation of smart growth policies that serve to densify and concentrate growth in areas with sufficient infrastructure and services to support it. Infill rates, the proportion of growth in urban areas, and urban housing and job densities all increase by up to $10 \%$ at the beginning of the initial time step. The percentage increase is weighted by the residential probability surface. Sewer service areas are expanded by $1.6 \mathrm{~km}$ and future growth is prohibited on soils unsuitable for septic systems. ${ }^{2}$

\subsubsection{Natural land conservation (FC)}

The FC scenario represents the immediate implementation of aggressive natural land conservation zoning, ordinances, easements, and acquisition. Under this scenario, growth is excluded from all-natural lands' riparian zones, wetlands, areas subject to a 1-m rise in sea level, lands within $1.6 \mathrm{~km}$ of National Wildlife Refuges, large natural land tracts $\left(>1 \mathrm{~km}^{2}\right)$, lands within $305 \mathrm{~m}$ of the tidal and coastal shorelines, and other natural lands with high conservation values.

\subsubsection{Agricultural conservation (AC)}

The AC scenario represents the immediate implementation of aggressive agricultural land conservation zoning, ordinances, easements, and acquisition. Under this scenario, growth is excluded from designated Agricultural Districts, floodplains, prime agricultural lands and those of state importance, prior converted wetlands, and farms with other high conservation values.

\section{Results}

\subsection{Model calibration and validation}

Model performance statistics with respect to daily runoff for the downstream gaging station were: $\mathrm{NSE}=0.73 ; \mathrm{R}^{2}=0.82 ; \mathrm{PBIAS}=12.3 \%$ for calibration, and NSE $=0.66 ; \mathrm{R}^{2}=0.73$; PBIAS $=17.8 \%$ for validation. The results indicated that the model was able to predict runoff reasonably well (Moriasi et al., 2015; Ahmadisharaf et al., 2019) during decades of watershed modeling. For example, Moriasi et al. (2015) reported $\mathrm{R}^{2}$ of $0.7-0.8$ as a good agreement. Allen et al. (2007); Moriasi et al. (2015); Ritter and Munoz-Carpena (2013) reported NSEs in the range of $0.65-0.75$ as a good agreement. Moriasi et al. (2015) also reported PBIAS of $5 \%-15 \%$ as a good agreement.

\footnotetext{
${ }^{2}$ Unsuitable soils based on depth to bedrock, drainage class, saturated hydraulic conductivity, and flood frequency.
}

Hydraulic conductivity, imperviousness, and hydraulic width were the most sensitive calibration parameters based on sensitivity analysis via RSWMM-Cost (Alamdari and Sample, 2019); each parameter was adjusted to maximize the correlation and minimize errors between observed and simulated streamflow. Unsurprisingly, imperviousness was the most sensitive parameter, in agreement with previous studies (Baffaut and Delleur, 1990; Barco et al., 2008; Boon et al., 2008; Nayeb Yazdi et al., 2019a). Hydraulic conductivity and hydraulic width did not have substantial effects on runoff, but they did affect the shape of the hydrograph. Calibration and validation for runoff are shown in Fig. 2.

An assessment of water quality calibration was performed by comparing simulated against water quality data along with the same watershed delineation that represents BRW within the CBWM model, and calibration results showed an $\mathrm{R}^{2}$ of $0.65,0.69$, and 0.59 , for TSS, TN, and TP, respectively. Prediction of water quality seems less accurate than runoff (based on $\mathrm{R}^{2}$ during the calibration), primarily due to the limited water quality data available and the use of another model (CBWM) for comparisons, yet the calibration results indicated that predicted data and CBWM data were in fair agreement, according to the criteria by Moriasi et al. (2015) and Ahmadisahraf et al. (2019), so the model is acceptable for use for water quality simulation.

\subsection{Projected climate change}

Average monthly temperatures for the baseline and projected scenarios for the two GCM models (median of two models) for RCP 4.5 and RCP 8.5 are presented in Fig. 3. The watershed annual average temperature is projected to increase by $2.03^{\circ} \mathrm{C}$ and $2.68{ }^{\circ} \mathrm{C}$ for RCP 4.5 and RCP 8.5, respectively, compared to the baseline period. The greatest temperature change occurred between June-August, between $2.0{ }^{\circ} \mathrm{C}$ and $2.4{ }^{\circ} \mathrm{C}$. Overall, annual precipitation is projected to increase between $6 \%$ and $17 \%$. The results indicated that RCP 8.5 results in a greater increase in annual precipitation than RCP 4.5. The maximum increase in precipitation occurred during the winter season within a range from $16.1 \%$ to $18.8 \%$. Overall, for both climate change scenarios, precipitation and temperature are projected to increase.

\subsection{Projected runoff and pollutant loads}

Annual runoff from the watershed is projected to increase for both RCPs (Fig. 4). The average annual runoff is projected to increase by $10.6 \%$ for RCP 4.5 and $28.2 \%$ for RCP 8.5 . During the winter season (Fig. 5), runoff was projected to increase $32.6 \%$ for RCP 8.5 . Analyses of daily results also indicate a projected increase in runoff especially for RCP 8.5 with a median change of $20.9 \%$ (Fig. 6).

Annual runoff from the BRW is projected to increase for LULC change alone. The average annual runoff is projected to increase by $14.1 \%$, $17.8 \%, 16.3 \%$, and $31.5 \%$ for the AC, FC, GM, and HT scenarios, respectively (Fig. 4). Runoff changes can be explained by an increase in imperviousness and reduction in grassland and forest, particularly in the HT scenario. During the winter season, runoff is projected to increase as much as $33.1 \%$ for the HT scenario (Fig. 5). Analyses of daily results indicate a projected increase in runoff, particularly for the HT scenario, with a median change of $32.7 \%$ (Fig. 6).

The combined impact of climate and LULC changes indicates a projected increase in runoff for the entire period, especially for the combined RCP 8.5 - HT scenario simulation (Fig. 4). The average annual runoff is projected to increase by $26.1 \%, 30.2 \% 28.5 \%$, and $45.1 \%$ for the combination of the RC 4.5 and AC, FC, GM, and HT scenarios, respectively. The average annual runoff is projected to increase by $45.8 \%, 50.5 \%, 48.6 \%$, and $67.6 \%$ for the combination of the RC 8.5 and AC, FC, GM, and HT scenarios, respectively. All LULC change scenarios are projected to increase in runoff for the 2040-2060 period. During the winter season, runoff is projected to increase up to $62.3 \%$ for the RCP 4.5 and HT scenarios and up to $73.1 \%$ for the RCP 8.5 and HT scenarios (Fig. 5). Analyses of daily results also indicate a projected increase in 


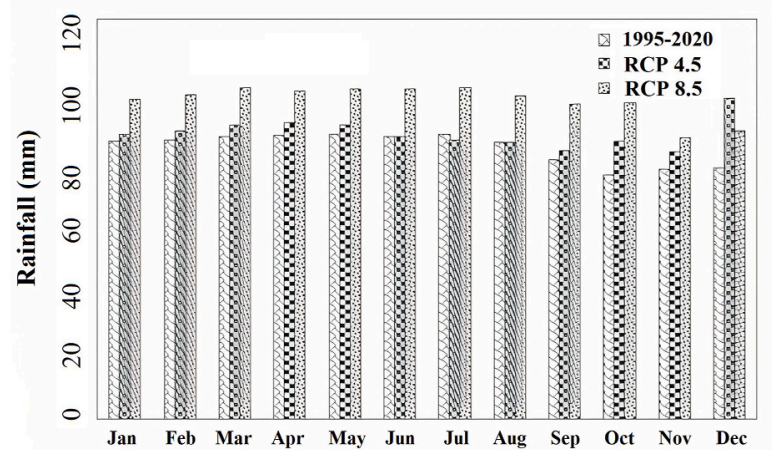

(a)

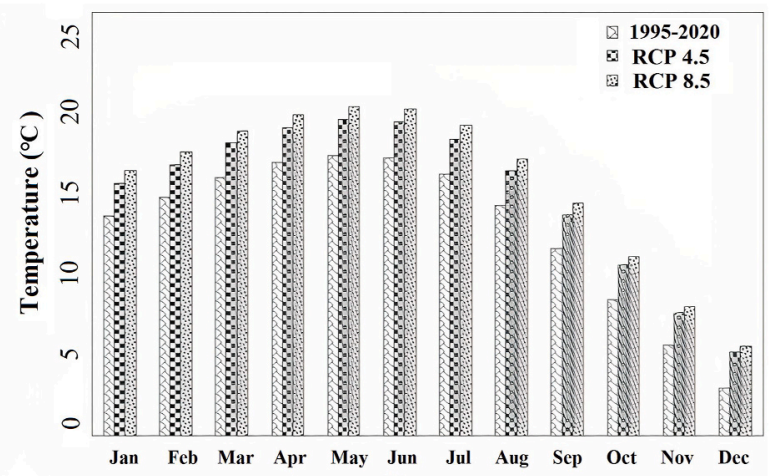

(b)

Fig. 3. Average monthly (a) precipitation, (b) temperature for the historical data (2000-2020), and the projected emission scenarios (2040-2065).
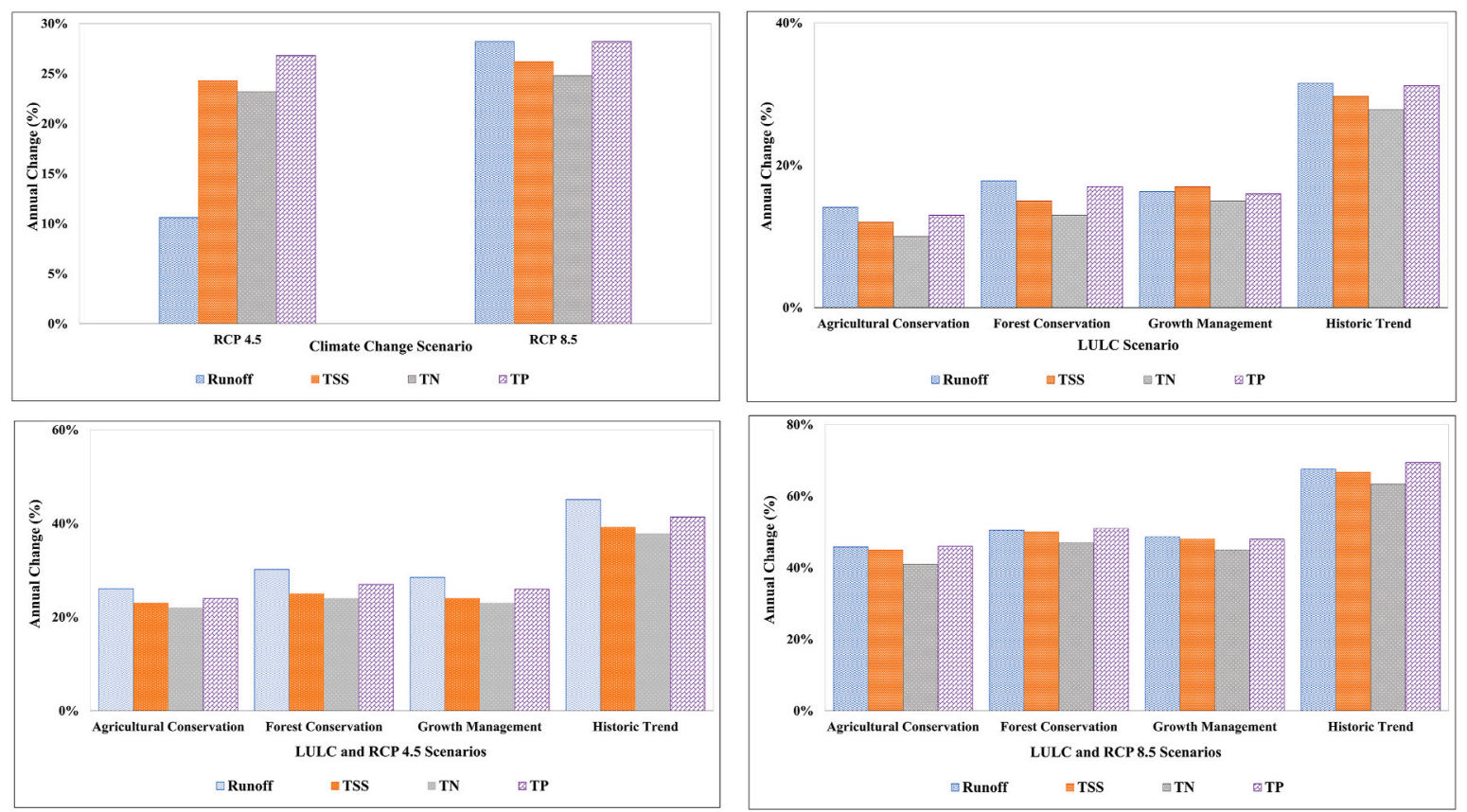

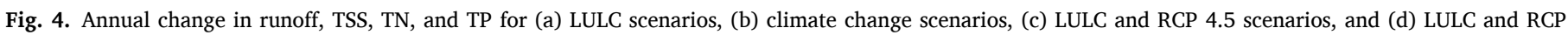
8.5 scenarios.

runoff, especially for the RCP 8.5 and HT scenarios with a median change of $56.1 \%$ (Fig. 6).

Annual TSS, TN, and TP loads from the watershed are projected to increase when only climate change was considered for both RCP 4.5 and RCP 8.5 scenarios (Fig. 4). Average annual TSS, TN, and TP loads are projected to increase by $24.3 \%, 23.2 \%, 26.8 \%$ for the RCP 4.5 scenario, respectively, and $26.2 \%, 24.8 \%$, and $28.2 \%$ for RCP 8.5 scenarios, respectively. The pollutant load changes can be explained by increases in the runoff. During the winter season, TSS, TN, and TP are projected to increase up to $33.4 \%, 31.6 \%$, and $35.8 \%$ for the RCP 8.5 scenario, respectively (Fig. 5). Analysis of daily results also indicates a projected increase in TSS, TN, and TP, particularly for the RCP 8.5 scenario, with a median change of $13.8 \%, 12.5 \%$, and $15.3 \%$, respectively (Fig. 6).

Annual TSS, TN, and TP loads from the watershed are projected to increase for LULC change, with the highest increase of $29.7 \%, 27.8 \%$, and $31.2 \%$, respectively, for the HT scenario (Fig. 4). During the fall season, TSS, TN, and TP are projected to increase up to $34.3,33.2 \%$, and $36.1 \%$ for the HT scenario (Fig. 5). Analyses of daily results also indicate a projected increase in runoff, especially for the HT scenario with a median change of $29.5 \%, 27.8 \%$, and $31.6 \%$ for TSS, TN, and TP, respectively (Fig. 6).
Annual TSS, TN, and TP loads from the watershed are projected to increase for the combination of climate and LULC change scenarios with the greatest projected increase of $39.2 \%, 37.8 \%$, and $41.3 \%$, respectively, occurring with the RCP 4.5 and HT scenarios, and $66.7 \%, 63.4 \%$, and $69.4 \%$, respectively, occurring with the RCP 8.5 and HT scenarios (Fig. 4). During the fall season, TSS, TN, and TP were projected to increase up to $46.4,45.2 \%$, and $49.1 \%$, respectively, for the RCP 4.5 and HT scenarios, and increase up to $54.9 \%, 53.1 \%$, and $56.6 \%$, respectively with the RCP 8.5 and HT scenarios (Fig. 5). Analysis of daily results also indicates a projected increase in TSS, TN, and TP loads, particularly for the HT and RCP 8.5 scenarios, with a median change of $54.5 \%, 52.2 \%$, and $56.9 \%$ for TSS, TN, and TP, respectively (Fig. 6).

An increase in runoff and pollutant loads is projected for LULC change alone, without climate change, due to a reduction in deciduous forest and grassland, and increased imperviousness (Fig. 7 and Table 3). For the combined impact of climate and LULC change, TSS, TN, and TP loads from the watershed are projected to increase. However, LULC change alone will yield more TSS and nutrients than climate change alone will, as shown in Fig. 7, Fig. S1 (Appendix), and Fig. S2 (Appendix). Thus, future LULC activities play an important role in either controlling or exacerbating sources of pollution in the BRW. 


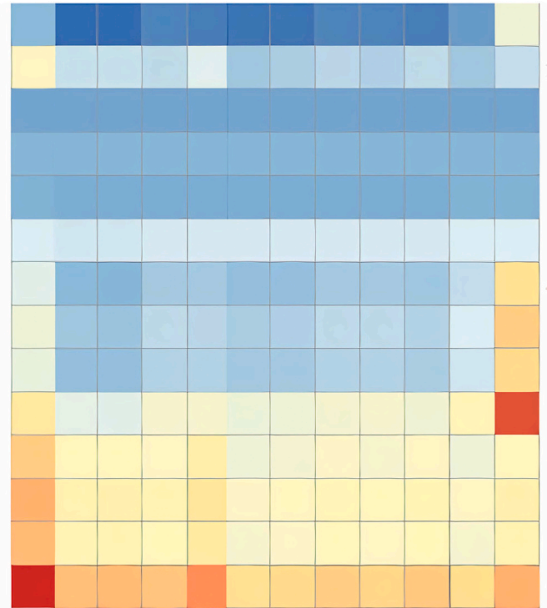

Runoff

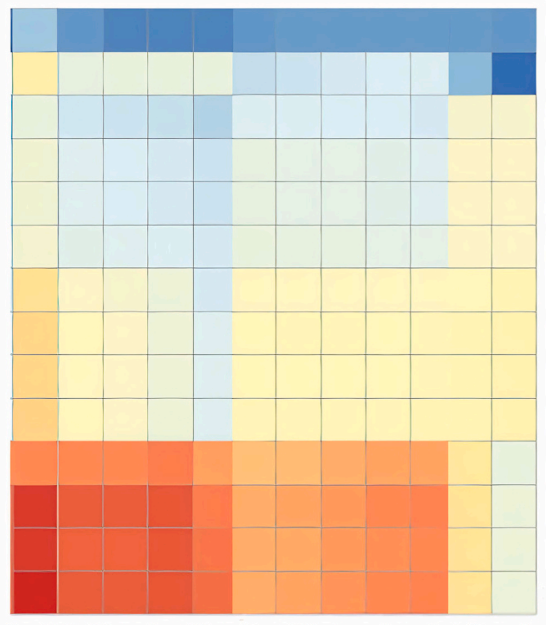

Jan Feb Mar Apr May Jun Jul Aug Sep Oct Nov De Total Nitrogen

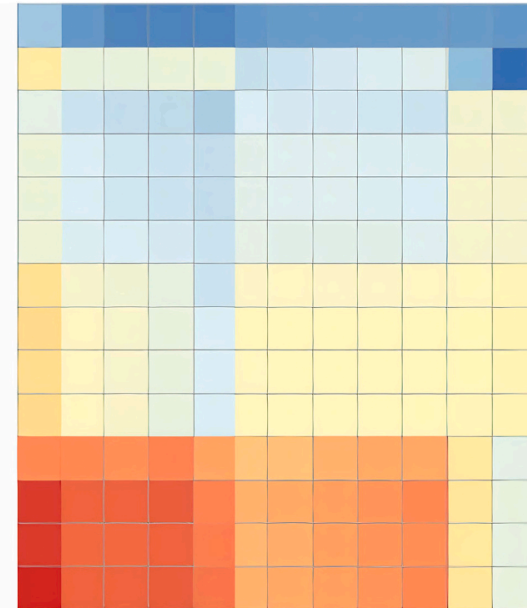

Total Suspended Solids

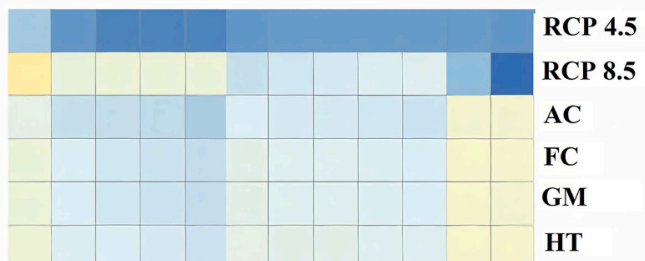

AC-RCP 4.5

FC-RCP 4.5

GM-RCP 4.5

HT-RCP 4.5

AC-RCP 8.5

FC-RCP 8.5

GM-RCP 8.5

HT-RCP 8.5
RCP 4.5

AC

GM

AC-RCP 4.5

FC-RCP 4.5

GM-RCP 4.5

P 4.5

FC-RCP 8.5

GM-RCP 8.5

HT-RCP 8.5

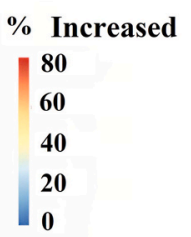

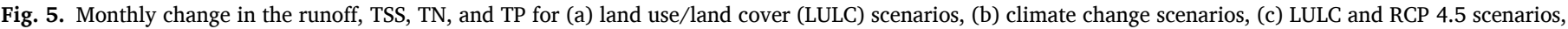
and (d) LULC and RCP 8.5 scenarios.

As shown in Table 3, the percentage of urban development and wetlands have increased more during the HT scenario compared to other LULC scenarios. This indicates that each LULC scenarios have diverse impacts on runoff and pollutant loading.

\section{Discussion}

These results indicate that for the BRW, runoff, TSS, TN, and TP are projected to increase for both RCP 4.5 and 8.5. Our results were in agreement with the results of Najjar et al. (2010), and Wagena et al. (2018), who predicted that runoff and sediment in the Chesapeake Bay watershed would increase as a result of climate change. Our research is the first study in the Chesapeake Bay watershed to evaluate the combined effects of climate and LULC changes on runoff and pollutant loads in a rapidly developing watershed that is tributary to the Bay. Climate models were used to predict the changes in temperature and precipitation. The climate models and associated greenhouse emission scenarios have different configurations and algorithms to project climate variables such as precipitation and temperature. This is the main reason that an ensemble approach is required to account for the variability of climate models to estimate the range of expected outcomes. The results of projected climate change indicate that the largest increase in precipitation, runoff, and pollutant loading would occur in winter and the largest temperature increase would be in summer for both RCP 4.5 and RCP 8.5 scenarios. These results agree with other studies in the Mid-Atlantic region such as Alamdari et al. (2020, 2017); Chang et al. (2001); Cousino et al. (2015); Najjar et al. (2010), and Wagena et al. (2018). Much of the variability in runoff is driven by precipitation. This was also observed in Wagena et al. (2018). The Northeast United States, including the Chesapeake Bay watershed, has been characterized as a region of increasing flow, particularly in extreme wet events, consistent with precipitation trends (Groisman et al., 1999, 2004; Najjar et al., 2010). An increase in sediment was primarily due to increased precipitation, imperviousness, and resulting runoff due to climate and LULC change, particularly during winter and spring. The increase in TSS, TN, and TP may have substantial effects on Chesapeake Bay functions and lead to the production of harmful algal blooms, reduction in aquatic habitat, and failure of stormwater management systems. Imperviousness is an important factor controlling the generation of runoff, TSS, TN, and $\mathrm{TP}$, and dramatically changed streamflow in the watershed. Our results indicated that the LULC change had greater effects on runoff generation and water quality than climate change did, similar to what was observed by Caldwell et al. (2012).

Although several studies in the Mid-Atlantic region focus on the effects of urbanization on runoff and pollutant loads (e.g., Roberts et al., 2009), our analyses indicate that other LULC classes, including 

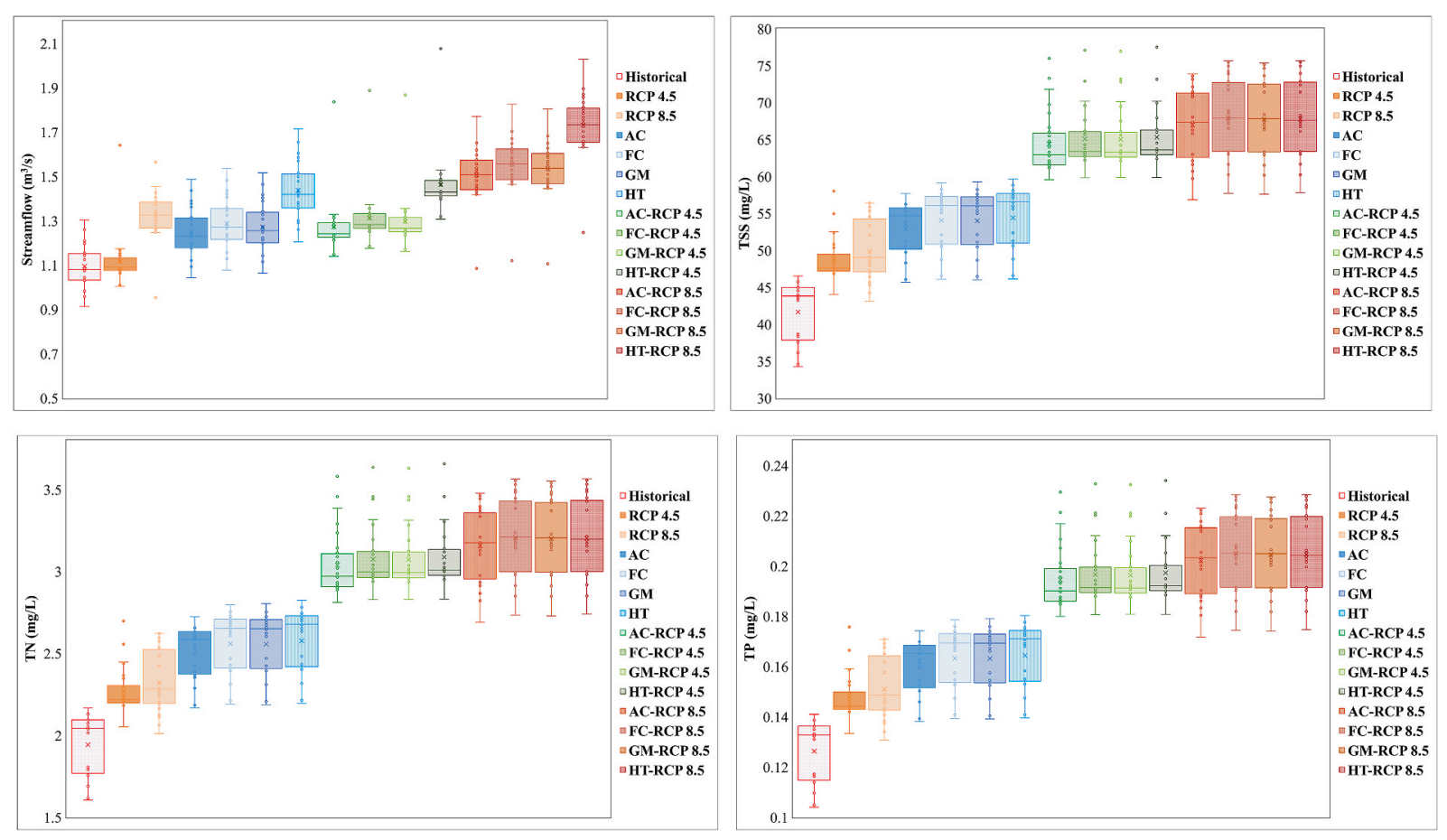

Fig. 6. Daily average runoff, TSS, TN, and TP for (a) LULC scenarios, (b) climate change scenarios, (c) LULC and RCP 4.5 scenarios, and (d) LULC and RCP 8.5 scenarios.

grassland and forest, also influence the results based on the comparison of historical and future LULC scenarios, which is consistent with Ahmadisharaf et al. (2020) and Lacher et al. (2019). The results may be different for areas subjected to intensive agriculture or silviculture. However, the effects depend on the type and extent of LULC change (Mehdi et al., 2015), watershed characteristics, and climate conditions; and thus, the changes in one may increase the impacts of the other.

The results indicate an increased runoff and pollutant loads due to LULC change, which is the result of changes in imperviousness and EMCs. EMCs have been used in the model for predicting water quality impacts from runoff. EMC values have been assigned to various LULCs and as urban areas increase and forested areas decrease, pollutant loads increase due to higher EMCs. Several factors, including impervious area and LULC, have long been recognized to influence wash-off processes and EMC values (Egodawatta et al., 2007; Muthusamy et al., 2018; Nayeb Yazdi et al., 2021; Perera et al., 2021). Our study is in agreement with these studies, due to increases in land uses associated with higher EMC values. The result of our study also indicates that runoff, TSS, TN, and TP are expected to be more affected by future LULC changes than climate change. This result has been confirmed by Guo et al. (2020); Hovenga et al. (2016); Hung et al. (2020); and Sun et al. (2020). In addition, the coupled response of climate and LULC change would likely result in larger values than would have been from their sum estimated separately. These findings are consistent with the studies by Giri et al. (2019); Luo et al. (2020); and Serpa et al. (2017) who reported that climate and LULC change would amplify the other's effects on nutrient loads. However, a study conducted by Laux et al. (2017) found that climate and LULC change would weaken each other's effects as they found smaller values than that estimated from the individual nonstationary stressor. Variability in the results may be due to regional hydrological processes suggesting the need for coupling climate change and LULC change. As the BRW is undergoing more urbanization at the expense of forest and grassland areas, the potential for increased runoff and nutrient loading should be considered by urban planners and decision-makers. As part of the Chesapeake Bay initiative, insight into how tributary watersheds such as Broad Run may respond to projected climate and LULC change may help better manage downstream hydrologic systems. Our analyses suggested that climate and LULC change should be incorporated in watershed models to evaluate their effects on hydrological processes to better understand the effects of these two nonstationary factors on hydrological processes. The result of our study can inform watershed restoration efforts, urban planning, and environmental policy. Climate and LULC change work in tandem and will likely generate increased runoff, and nutrient loading, indicating that mitigation strategies such as BMPs are needed for watershed restoration. Understanding the individual and coupled effects of climate and LULC change is needed to formulate better watershed restoration strategies in a changing environment and to minimize the adverse impact of these nonstationary stressors. Large increases in runoff due to the combination of climate and LULC change suggest the need for mitigation measures that employ ecological features, while also providing social and economic benefits.

This work provides an assessment of the consequences of combined climate and LULC changes in a rapidly urbanizing watershed tributary to the Chesapeake Bay and suggests how stakeholders might adapt management strategies to address or adapt to projected changes. This is a critical step in identifying pollutant sources and reducing water quality impacts, as the largest and most expensive watershed restoration to date (the Chesapeake Bay) is implemented. This project also provides information about future nutrient loading that can guide water resources managers to develop new strategies for reducing water pollution. This information is timely, considering the schedule of the TMDL, and thus the outcomes could have broad impacts on the Chesapeake Bay watershed. Our methodology can be extended to other regions similarly impacted by urban growth. The results from this project can be broadly applicable to other metropolitan areas discharging sensitive water bodies.

The limitations of this study can be attributed to uncertainty in climate models, future emission of greenhouse gases, and input parameters for input to watershed models. A full analysis of uncertainty is recommended for future research. We used a quantile mapping approach for downscaling climate data; one potential shortcoming of this method is the assumption that biases relative to historic observations are constant during future periods. However, compared to other 

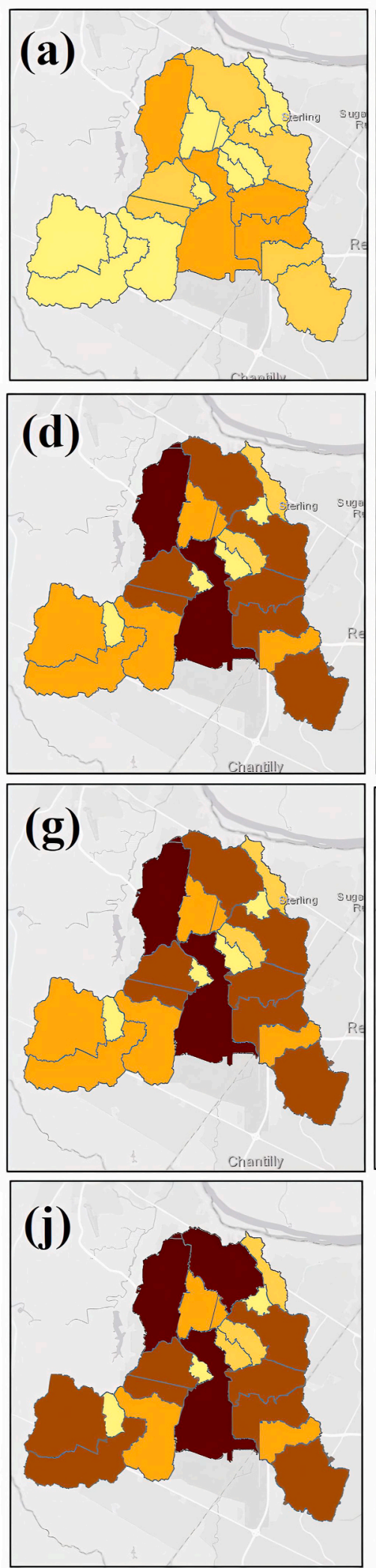
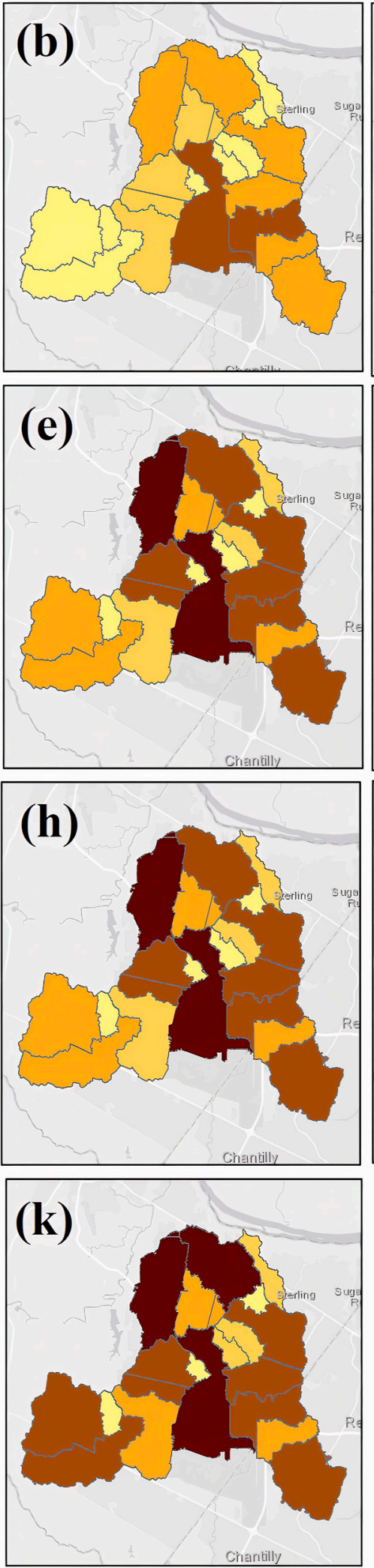
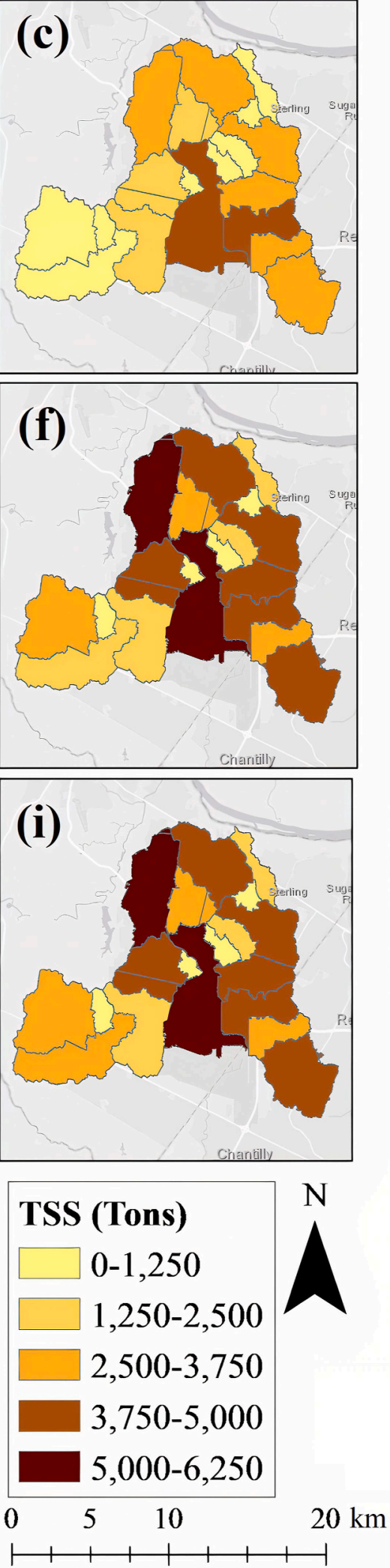

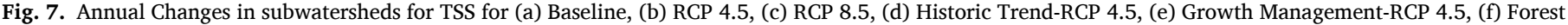

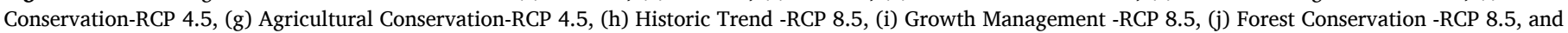
(k) Agricultural Conservation -RCP 8.5. 
Table 3

Land use/land cover percentage for each LULC scenario.

\begin{tabular}{llllll}
\hline $\begin{array}{l}\text { LULC } \\
\text { Type }\end{array}$ & 2011 & $\begin{array}{l}\text { Agricultural } \\
\text { Conservation }\end{array}$ & $\begin{array}{l}\text { Forest } \\
\text { Conservation }\end{array}$ & $\begin{array}{l}\text { Growth } \\
\text { Management }\end{array}$ & $\begin{array}{l}\text { Historic } \\
\text { Trend }\end{array}$ \\
\hline Urban & 52.7 & 63.9 & 68.5 & 63.8 & 69.8 \\
Forest & 20.8 & 13.3 & 15 & 15.6 & 9 \\
Barren & 0.8 & 0.8 & 0.8 & 0.8 & 0.8 \\
Water & 0.2 & 0.2 & 0.2 & 0.2 & 0.2 \\
Wetland & 4.1 & 5.1 & 7.3 & 6.8 & 14.1 \\
Grassland & 20.9 & 16.7 & 8.2 & 12.8 & 6.9 \\
\hline
\end{tabular}

bias correction techniques, quantile mapping is efficient in removing bias, performs well for downscaling precipitation extremes, and has the benefit of accounting for GCM biases across all statistical moments. For water quality, SWMM only accounts for LULC, which is considered a lumped characteristic and does not consider site-specific characteristics, pollutant features, and rainfall properties and patterns at the same time. Thus, the complexity associated with pollutant build-up and wash-off and other in-depth investigations should be considered in current stormwater models to adequately represent important processes and parameters for water quality modeling and pollutant transport.

\section{Conclusions}

In this study, an urban watershed model (SWMM) was used to evaluate the effects of climate and LULC changes on runoff and pollutant loading from the BRW. The model was calibrated based on observed runoff quantity and simulated water quality; the latter using HSPFgenerated data from the CBWM. The calibrated SWMM model was employed to predict runoff and pollutant loads for climate and LULC change scenarios for 2040-2065. LULC change resulted in a projected increase of imperviousness of $6.3 \%-13.1 \%$. The findings of our study suggest that the magnitude and extent of the climate change effects depend on the RCP used. LULC change alone increased runoff, TSS, TN, and TP, but the changes varied noticeably according to the LULC scenario. The combined effects of climate and LULC change showed the largest projected increase in runoff and pollutant loads for the RCP 8.5 and HT scenarios, due to a reduction in forest and grassland, and the largest increase in imperviousness. The combination of climate and LULC change revealed that the changes in one may increase the effects of the other.

LULC change coupled with climate change may accelerate pollutant transport from the BRW to sensitive receiving waters such as the Chesapeake Bay. This research suggests that runoff and pollutant loads will likely increase in the future, so, proper mitigation strategies such as BMPs should be implemented to minimize the negative impacts of climate and LULC changes.

There are various types of BMPs available for managing stormwater that have different pollutant removal capabilities. Several factors should be considered when selecting appropriate BMPs such as space requirements, operation and maintenance, cost, and community approval. The modeling framework described herein is transferable to other watersheds with similar conditions and can be used to identify and evaluate mitigation strategies.

\section{Declaration of competing interest}

None.

\section{Acknowledgments}

The authors express their appreciation to Ray Najjar of Penn State University, John Jastram of the USGS, Darold Burdick and Daniel Habete of Fairfax County, David Ward of Loudoun County, and Celso Ferreira of George Mason University, who facilitated this research. Support for this research was provided by the National Science
Foundation, Water Sustainability and Climate WSC-Category 1 Collaborative Project: Coupled Multi-Scale Economic, Hydrologic and Estuarine Modeling to assess Impacts of Climate Change on Water Quality Management, Grant \#23032, however, opinions expressed within are entirely those of the authors and reflect no endorsement by NSF or USGS. Any use of trade, firm, or product names is for descriptive purposes only and does not imply endorsement by the US Government. Funding for this work was provided in part by the Virginia Agricultural Experiment Station and the Hatch program, Project S1089, of the National Institute of Food and Agriculture, which also does not imply endorsement of opinions contained herein.

\section{Appendix A. Supplementary data}

Supplementary data to this article can be found online at https://doi. org/10.1016/j.jclepro.2021.129953.

\section{References}

Abrishamchi, A., Dashti, M., Alamdari, N., Salavitabar, A., 2011. A GIS-Google earth based approach to estimating the flood damage function in large river basins. In: World Environmental and Water Resources Congress 2011: Bearing Knowledge for Sustainability. Palm Springs, California, USA, pp. 3811-3821.

Ahmadisharaf, E., Alamdari, N., Tajrishy, M., Ghanbari, S., 2021. Effectiveness of retention ponds for sustainable urban flood mitigation across range of storm depths in Northern Tehran, Iran. J. Sustain. Water Built Environ. 7, 5021003.

Ahmadisharaf, E., Camacho, R.A., Zhang, H.X., Hantush, M.M., Mohamoud, Y.M., 2019. Calibration and validation of watershed models and advances in uncertainty analysis in TMDL studies. J. Hydrol. Eng. 24, 3119001.

Ahmadisharaf, E., Lacher, I.L., Fergus, C., Benham, B.L., Akre, T., Kline, K.S., 2020. Projecting land use change impacts on nutrients, sediment and runoff in multiple spatial scales: business-as-usual vs. stakeholder-informed scenarios. J. Clean. Prod. 257, 120466.

Ahmadisharaf, E., Tajrishy, M., Alamdari, N., 2016. Integrating flood hazard into site selection of detention basins using spatial multi-criteria decision-making. J. Environ. Plann. Manag. 59, 1397-1417.

Alamdari, N., 2018. Modeling Climate Change Impacts on the Effectiveness of Stormwater Control Measures in Urban Watersheds. Doctoral dissertation, Virginia Tech.

Alamdari, N., 2016. Development of a robust automated tool for calibrating a SWMM watershed model. In: World Environmental and Water Resources Congress 2016, p. 221. West Palm Beach, FL.

Alamdari, N., Hogue, T.S., 2021. Assessing the effects of climate change on urban watersheds: a review and call for future research. Environ. Rev. https://doi.org/ 10.1139/er-2021-0003.

Alamdari, Nasrin, Sample, D., Steinberg, P., Ross, A., Easton, Z., 2017. Assessing the effects of climate change on water quantity and quality in an urban watershed using a calibrated stormwater model. Water 9, 464.

Alamdari, N., Sample, D.J., 2019. A multiobjective simulation-optimization tool for assisting in urban watershed restoration planning. J. Clean. Prod. 213, 251-261.

Alamdari, N., Sample, D.J., Liu, J., Ross, A., 2018. Assessing climate change impacts on the reliability of rainwater harvesting systems. Resour. Conserv. Recycl. 132, 178-189.

Alamdari, N., Sample, D.J., Ross, A.C., Easton, Z.M., 2020. Evaluating the impact of climate change on water quality and quantity in an urban watershed using an ensemble approach. Estuar. Coast 43, 56-72.

Allen, R.G., Tasumi, M., Trezza, R., 2007. Satellite-based energy balance for mapping evapotranspiration with internalized calibration (METRIC) - Model. J. Irrigat. Drain. Eng. 133, 380-394.

Baffaut, C., Delleur, J.W., 1990. Calibration of SWMM runoff quality model with expert system. J. Water Resour. Plann. Manag. 116, 247-261.

Barco, J., Wong, K.M., Stenstrom, M.K., 2008. Automatic calibration of the US EPA SWMM model for a large urban catchment. J. Hydraul. Eng. 134, 466-474.

Boon, T.S., Hock, C.L., Ban, S.E., Yat-Man, L.E., Wan, L.L., 2008. Performances of rainfall-runoff models calibrated over single and continuous storm flow events. J. Hydrol. Eng. 13, 597-607.

Bosch, D.J., Wagena, M.B., Ross, A.C., Collick, A.S., Easton, Z.M., 2018. Meeting water quality goals under climate change in Chesapeake Bay watershed, USA. JAWRA J. Am. Water Resour. Assoc. 54, 1239-1257.

Caldwell, P.V., Sun, G., McNulty, S.G., Cohen, E.C., Moore Myers, J.A., 2012. Impacts of impervious cover, water withdrawals, and climate change on river flows in the conterminous US. Hydrol. Earth Syst. Sci. 16, 2839-2857.

Chang, H., Evans, B.M., Easterling, D.R., 2001. The effects of climate change on stream flow and nutrient loading. JAWRA J. Am. Water Resour. Assoc. 37, 973-985.

Claggett, P., 2011. The Chesapeake Bay land change model. Trend Scenario [WWW Document]. URL. https://pubs.usgs.gov/of/2012/1216/Presentations/Peter_Clagge tt.pdf.

Claggett, P., Thompson, R., 2012. Proceedings of the Workshop on Alternative FuturesAccounting for Growth in the Chesapeake Bay Watershed: U.S. Geological Survey Open-File Report 2012-1216. U.S. Geological Survey. 
Cousino, L.K., Becker, R.H., Zmijewski, K.A., 2015. Modeling the effects of climate change on water, sediment, and nutrient yields from the Maumee River watershed J. Hydrol. Reg. Stud. 4, 762-775.

Donigian Jr., A.S., Bicknell, B.R., Imhoff, J.C., 1995. Hydrological simulation programfortran (HSPF). Comput. Model. watershed Hydrol. 395-442.

Drake, A.A., Lee, K.Y., 1989. Geologic Map of the Vienna Quadrangle, Fairfax County, Virginia, and Montgomery County, Maryland. U.S. Geological Survey, Washington, DC.

Egodawatta, P., Thomas, E., Goonetilleke, A., 2007. Mathematical interpretation of pollutant wash-off from urban road surfaces using simulated rainfall. Water Res. 41, 3025-3031.

Fisher, T.R., Fox, R.J., Gustafson, A.B., Koontz, E., Lepori-Bui, M., Lewis, J., 2021. Localized water quality improvement in the choptank estuary, a tributary of Chesapeake Bay. Estuar. Coast 44, 1274-1293.

Fleming, B.J., Archfield, S.A., Hirsch, R.M., Kiang, J.E., Wolock, D.M., 2021. Spatial and temporal patterns of low streamflow and precipitation changes in the Chesapeake Bay Watershed. JAWRA J. Am. Water Resour. Assoc. 57, 96-108.

Foley, J.A., DeFries, R., Asner, G.P., Barford, C., Bonan, G., Carpenter, S.R., Chapin, F.S., Coe, M.T., Daily, G.C., Gibbs, H.K., Helkowski, J.H., Holloway, T., Howard, E.A., Kucharik, C.J., Monfreda, C., Patz, J.A., Prentice, I.C., Ramankutty, N., Snyder, P.K., 2005. Global consequences of land use. Science 84 309, 570-574. LP -.

Giri, S., Arbab, N.N., Lathrop, R.G., 2019. Assessing the potential impacts of climate and land use change on water fluxes and sediment transport in a loosely coupled system. J. Hydrol. 577, 123955.

Giuffria, J.M., Bosch, D.J., Taylor, D.B., Alamdari, N., 2017. Costs of water quality goals under climate change in urbanizing watersheds: difficult run, Virginia. J. Water Resour. Plann. Manag. 143, 4017055.

Groisman, P.Y., Karl, T.R., Easterling, D.R., Knight, R.W., Jamason, P.F., Hennessy, K.J., Suppiah, R., Page, C.M., Wibig, J., Fortuniak, K., 1999. Changes in the probability of heavy precipitation: important indicators of climatic change. In: Weather and Climate Extremes. Springer, pp. 243-283.

Groisman, P.Y., Knight, R.W., Karl, T.R., Easterling, D.R., Sun, B., Lawrimore, J.H., 2004 Contemporary changes of the hydrological cycle over the contiguous United States: trends derived from in situ observations. J. Hydrometeorol. 5, 64-85.

Guo, Y., Fang, G., Xu, Y.-P., Tian, X., Xie, J., 2020. Identifying how future climate and land use/cover changes impact streamflow in Xinanjiang Basin, East China. Sci. Total Environ. 710, 136275.

Hargreaves, G.H., Samani, Z.A., 1985. Reference crop evapotranspiration from temperature. Appl. Eng. Agric. 1, 96-99.

Hathaway, J.M., Brown, R.A., Fu, J.S., Hunt, W.F., 2014. Bioretention function under climate change scenarios in North Carolina, USA. J. Hydrol. 519, 503-511.

Homer, C.H., Fry, J.A., Barnes, C.A., 2012. The national land cover database. US Geol, Surv. Fact Sheet 3020, 1-4.

Hovenga, P.A., Wang, D., Medeiros, S.C., Hagen, S.C., Alizad, K., 2016. The response of runoff and sediment loading in the Apalachicola River, Florida to climate and land use land cover change. Earth's Futur 4, 124-142.

Hung, C.-L.J., James, L.A., Carbone, G.J., Williams, J.M., 2020. Impacts of combined land-use and climate change on streamflow in two nested catchments in the Southeastern United States. Ecol. Eng. 143, 105665.

IPCC, 2014. Climate Change 2014-Impacts, Adaptation and Vulnerability: Regional Aspects. Cambridge University Press.

Jefferson, A.J., Bhaskar, A.S., Hopkins, K.G., Fanelli, R., Avellaneda, P.M., McMillan, S. K., 2017. Stormwater management network effectiveness and implications for urban watershed function: a critical review. Hydrol. Process. 31, 4056-4080.

Johnson, T., Butcher, J., Parker, A., Weaver, C., 2012. Investigating the sensitivity of U.S streamflow and water quality to climate change: U.S. EPA global change research program's 20 watersheds project. J. Water Resour. Plann. Manag. 138, 453-464.

Jordan, T.E., Weller, D.E., Pelc, C.E., 2018. Effects of local watershed land use on water quality in mid-Atlantic coastal bays and subestuaries of the Chesapeake Bay. Estuar. Coast 41, 38-53.

Kalantari, Z., Ferreira, C.S.S., Page, J., Goldenberg, R., Olsson, J., Destouni, G., 2019. Meeting sustainable development challenges in growing cities: coupled socialecological systems modeling of land use and water changes. J. Environ. Manag. 245, 471-480.

Kleinman, P.J.A., Fanelli, R.M., Hirsch, R.M., Buda, A.R., Easton, Z.M., Wainger, L.A., Brosch, C., Lowenfish, M., Collick, A.S., Shirmohammadi, A., 2019. Phosphorus and the Chesapeake Bay: lingering issues and emerging concerns for agriculture. J. Environ. Qual. 48, 1191-1203.

Lacher, I.L., Ahmadisharaf, E., Fergus, C., Akre, T., Mcshea, W.J., Benham, B.L., Kline, K. S., 2019. Scale-dependent impacts of urban and agricultural land use on nutrients, sediment, and runoff. Sci. Total Environ. 652, 611-622.

Laux, P., Nguyen, P.N.B., Cullmann, J., Kunstmann, H., 2017. Impacts of land-use/landcover change and climate change on the regional climate in the central Vietnam. In: Land Use and Climate Change Interactions in Central Vietnam. Springer, pp. 143-151.

Lintern, A., McPhillips, L., Winfrey, B., Duncan, J., Grady, C., 2020. Best management practices for diffuse nutrient pollution: wicked problems across urban and agricultural watersheds. Environ. Sci. Technol. 54, 9159-9174.

Loudoun County, 2008. Comprehensive Watershed Management Plan.

Luo, C., Li, Z., Liu, H., Li, H., Wan, R., Pan, J., Chen, X., 2020. Differences in the responses of flow and nutrient load to isolated and coupled future climate and land use changes. J. Environ. Manag. 256, 109918.

Mehdi, B., Ludwig, R., Lehner, B., 2015. Evaluating the impacts of climate change and crop land use change on streamflow, nitrates and phosphorus: a modeling study in Bavaria. J. Hydrol. Reg. Stud. 4, 60-90.
Milly, P.C.D., Betancourt, J., Falkenmark, M., Hirsch, R.M., Kundzewicz, Z.W., Lettenmaier, D.P., Stouffer, R.J., Dettinger, M.D., Krysanova, V., 2015. On critiques of "Stationarity is dead: whither water management? Water Resour. Res. 51, 7785-7789.

D. Moriasi, D.N., Gitau, M.W., Pai, N., Daggupati, P., Moriasi, N., Gitau, W., Pai, N., Daggupati, P., 2015. Hydrologic and water quality models: performance measures and evaluation criteria, M. Trans. ASABE (Am. Soc. Agric. Biol. Eng.) 58, 1763-1785.

Moss, R.H., Edmonds, J.A., Hibbard, K.A., Manning, M.R., Rose, S.K., Van Vuuren, D.P., Carter, T.R., Emori, S., Kainuma, M., Kram, T., 2010. The next generation of scenarios for climate change research and assessment. Nature 463, 747.

Muthusamy, M., Tait, S., Schellart, A., Beg, M.N.A., Carvalho, R.F., de Lima, J.L.M.P., 2018. Improving understanding of the underlying physical process of sediment wash-off from urban road surfaces. J. Hydrol. 557, 426-433.

Najjar, R.G., Pyke, C.R., Adams, M.B., Breitburg, D., Hershner, C., Kemp, M., Howarth, R., Mulholland, M.R., Paolisso, M., Secor, D., Sellner, K., Wardrop, D., Wood, R., 2010. Potential climate-change impacts on the Chesapeake Bay. Estuar. Coast Shelf Sci. 86, 1-20.

National Research Council, 2000. Clean Coastal Waters: Understanding and Reducing the Effects of Nutrient Pollution. National Academies Press.

Natural Resources Conservation Service, 2015. Web Soil Survey [WWW Document]. URL. http://websoilsurvey.nrcs.usda.gov/.

Nayeb Yazdi, M., Ketabchy, M., Sample, D.J., Scott, D., Liao, H., 2019a. An evaluation of HSPF and SWMM for simulating streamflow regimes in an urban watershed. Environ. Model. Software 118, 211-225.

Nayeb Yazdi, M., Sample, D.J., Scott, D., Owen, J.S., Ketabchy, M., Alamdari, N., 2019b. Water quality characterization of storm and irrigation runoff from a container nursery. Sci. Total Environ. 667, 166-178.

Nayeb Yazdi, M., Sample, D.J., Scott, D., Wang, X., Ketabchy, M., 2021. The effects of land use characteristics on urban stormwater quality and watershed pollutant loads. Sci. Total Environ. 773, 145358.

Niazi, M., Nietch, C., Maghrebi, M., Jackson, N., Bennett, B.R., Tryby, M., Massoudieh, A., 2017. Storm water management model: performance review and gap analysis. J. Sustain. Water Built Environ., 4017002

Pan, S., Bian, Z., Tian, H., Yao, Y., Najjar, R.G., Friedrichs, M.A.M., Hofmann, E.E., $\mathrm{Xu}$, R., Zhang, B., 2021. Impacts of multiple environmental changes on long-term nitrogen loading from the Chesapeake Bay watershed. J. Geophys. Res. Biogeosciences 126, e2020JG005826.

Perera, T., McGree, J., Egodawatta, P., Jinadasa, K., Goonetilleke, A., 2021. New conceptualisation of first flush phenomena in urban catchments. J. Environ. Manag. $281,111820$.

Price, W.D., Burchell, M.R., Hunt, W.F., Chescheir, G.M., 2013. Long-term study of dune infiltration systems to treat coastal stormwater runoff for fecal bacteria. Ecol. Eng. $52,1-11$.

Rajaei, F., Dahmardeh Behrooz, R., Ahmadisharaf, E., Galalizadeh, S., Dudic, B., Spalevic, V., Novicevic, R., 2021. Application of integrated watershed management measures to minimize the land use change impacts. Water 13, 2039.

Ritter, A., Munoz-Carpena, R., 2013. Performance evaluation of hydrological models: statistical significance for reducing subjectivity in goodness-of-fit assessments. J. Hydrol. 480, 33-45.

Roberts, A.D., Prince, S.D., Jantz, C.A., Goetz, S.J., 2009. Effects of projected future urban land cover on nitrogen and phosphorus runoff to Chesapeake Bay. Ecol. Eng. $35,1758-1772$.

Rossman, L.A., 2015. Storm Water Management Model Reference Manual: Volume I-Hydrology. US Envrionmental Prot. Agency, Off. Res. Dev. Natl. Risk Manag. Lab. Cincinnati. OH 45268.

Roth, N., Voli, M., Schreiner, S., Boado, A., Brindley, A., Jones, T., Harriott, S., DewBaxter, J., Southerland, M., 2014. Upper Broad Run Watershed Management Plan.

Salvadore, E., Bronders, J., Batelaan, O., 2015. Hydrological modelling of urbanized catchments: a review and future directions. J. Hydrol. 529, 62-81.

Schilling, K.E., Chan, K.-S., Liu, H., Zhang, Y.-K., 2010. Quantifying the effect of land use land cover change on increasing discharge in the Upper Mississippi River. J. Hydrol. 387, 343-345.

Schilling, K.E., Jha, M.K., Zhang, Y., Gassman, P.W., Wolter, C.F., 2008. Impact of land use and land cover change on the water balance of a large agricultural watershed: historical effects and future directions. Water Resour. Res. 44.

Schueler, T., 2011. Ponds in the Chesapeake Bay watershed. In: Chesapeake Stormwater Partnership Retreat. Shepherdstown, WV.

Semadeni-Davies, A., Hernebring, C., Svensson, G., Gustafsson, L.-G., 2008. The impacts of climate change and urbanisation on drainage in Helsingborg, Sweden: suburban stormwater. J. Hydrol. 350, 114-125.

Semadeni-Davies, A., 2006. Winter performance of an urban stormwater pond in southern Sweden. Hydrol. Process. 20, 165-182.

Serpa, D., Nunes, J.P., Keizer, J.J., Abrantes, N., 2017. Impacts of climate and land use changes on the water quality of a small Mediterranean catchment with intensive viticulture. Environ. Pollut. 224, 454-465.

Sheffield, J., Barrett, A.P., Colle, B., Nelun Fernando, D., Fu, R., Geil, K.L., Hu, Q., Kinter, J., Kumar, S., Langenbrunner, B., 2013. North American climate in CMIP5 experiments. Part I: evaluation of historical simulations of continental and regional climatology. J. Clim. 26, 9209-9245.

Shenk, G.W., Linker, L.C., 2013. Development and application of the 2010 Chesapeake Bay watershed total maximum daily load model. J. Am. Water Resour. Assoc. 49, 1042-1056.

Southworth, S., Burton, W.C., Schindler, J.S., Froelich, A.J., 2006. Geologic Map of Loudoun County, Virginia. US Department of the Interior, US Geological Survey. 
Sun, P., Wu, Y., Wei, X., Sivakumar, B., Qiu, L., Mu, X., Chen, J., Gao, J., 2020. Quantifying the contributions of climate variation, land use change, and engineering measures for dramatic reduction in streamflow and sediment in a typical loess watershed, China. Ecol. Eng. 142, 105611.

Taylor, K.E., Stouffer, R.J., Meehl, G.A., 2012. An overview of CMIP5 and the experiment design. Bull. Am. Meteorol. Soc. 93, 485-498.

USEPA, 2010a. Chesapeake Bay Total Maximum Daily Load for Nitrogen, Phosphorous and Sediment in. USEPA Region III, Philadelphia, PA.
USEPA, 2010b. Guidance for Federal Land Management in the Chesapeake Bay

Watershed (Chapter 3). Urban and Suburban. U.S. Environmental Protection Agency, Washington, DC.

Wagena, M.B., Collick, A.S., Ross, A.C., Najjar, R.G., Rau, B., Sommerlot, A.R., Fuka, D. R., Kleinman, P.J.A., Easton, Z.M., 2018. Impact of climate change and climate anomalies on hydrologic and biogeochemical processes in an agricultural catchment of the Chesapeake Bay watershed. USA. Sci. Total Environ. 637, 1443-1454. Yan, B., Fang, N.F., Zhang, P.C., Shi, Z.H., 2013. Impacts of land use change on watershed streamflow and sediment yield: an assessment using hydrologic modelling and partial least squares regression. J. Hydrol. 484, 26-37. 